\title{
Research on Seamless Switching Control Strategy Based on Virtual Synchronous Generator
}

\author{
Wei Kang1, Jibo Wan², Lixia Zhang', Qilong Zhang1 \\ ${ }^{1}$ China University of Petroleum, Qingdao, China \\ ${ }^{2}$ Zibo Power Supply Company, Zibo, China \\ Email: kangwei@upc.edu.cn
}

How to cite this paper: Kang, W., Wan, J.B., Zhang, L.X. and Zhang, Q.L. (2017) Research on Seamless Switching Control Strategy Based on Virtual Synchronous Generator. Energy and Power Engineering, 9, 436-444.

https://doi.org/10.4236/epe.2017.94B049

Received: February 28, 2017

Accepted: March 30, 2017

Published: April 6, 2017

\begin{abstract}
This paper studies the voltage, phase and current tracking strategy to eliminate voltage and current mutations when the virtual synchronous generator is switching between grid-connected and islanded. By using these strategies the inverter can realize secondary frequency regulation and voltage regulation. If the phase is near 0 or $2 \pi$ a little disturbance may made the PLL output a big error, so a new PLL is proposed by this paper. A sine module is added in the PLL to avoid this error. In order to verify the strategy proposed by this paper a simulation model is built in Matlab/Simulink. The simulation results show that the control strategy can realize seamless switching.
\end{abstract}

\section{Keywords}

Virtual Synchronous Generator, PLL, Seamless Switching, Micro Grid

\section{Introduction}

Inverter is an important part of the new energy grid, its performance has great influence on the stability of the micro grid. The traditional control method generally uses PQ, VF and droop control mode [1] [2] [3] [4] [5]. The inverter operates in these modes do not have inertia, once power disturbance occurs, it is unable to provide support for the grid voltage and frequency, Therefore some scholars put forward the virtual synchronous generator control strategy [6] [7] [8] [9] [10]. By adding virtual inertia in the inverter control system, make the external characteristic of inverter similar to synchronous generator. In this paper, the control strategy of virtual synchronous generator is used to study seamless switching between grid-connected and islanding operation. And the phase lock loop used in control strategy is improved. 


\section{Virtual Synchronous Generator}

The control strategy of virtual synchronous generator is to simulate the mechanical characteristics and output power characteristics of a synchronous generator. In order to accurately simulate the mechanical inertia of the synchronous generator rotor, the equation of the synchronous generator is added. The rotor mechanical equation is as follows:

$$
\left\{\begin{array}{l}
\frac{d \delta}{d t}=\omega-\omega_{s} \\
T_{J} \frac{d \omega}{d t}=P_{m}-P_{e}-D\left(\omega-\omega_{s}\right)
\end{array}\right.
$$

In the formula, the $\omega$ is the generator speed, the $\omega_{s}$ is the synchronous speed, the $\delta$ represents the rotor angle of the generator, the $D$ indicates the damping coefficient, the $T_{J}$ is the generator inertia time constant, the $P_{m}$ represents the prime mover power, and the $P_{e}$ indicates the electromagnetic power.

By the formula (1) shows that when the load fluctuation, because the generator rotor mechanical inertia, the electromagnetic power could not immediately change, but from the original steady process gradually transition to the new steady state process. The transition time is determined by the load fluctuation, the generator inertia time constant $T_{J}$ and damping coefficient $D$. The generator inertia time constant $T_{J}$ plays a major role. The presence of $T_{J}$ does not change the system steady, but changed the transient time. When the load fluctuates, the system can not immediately adjust to the optimum frequency, but on the other hand, it avoids the system frequency change rapidly with the load fluctuation, is helpful to improve the stability of the system.

The control strategy of the virtual synchronous generator is shown in Figure 1.

The control strategy includes virtual inertia control module and the droop control module. The former is used to simulate the rotor motion equation to realize the dynamic frequency regulation. The latter is used to simulate the frequency regulation factor.

\section{Control Strategy between Islanded and Grid-Connected}

When the invert is switching between islanded and grid-connected, if do not control the related to electrical character, once the voltage amplitude, frequency

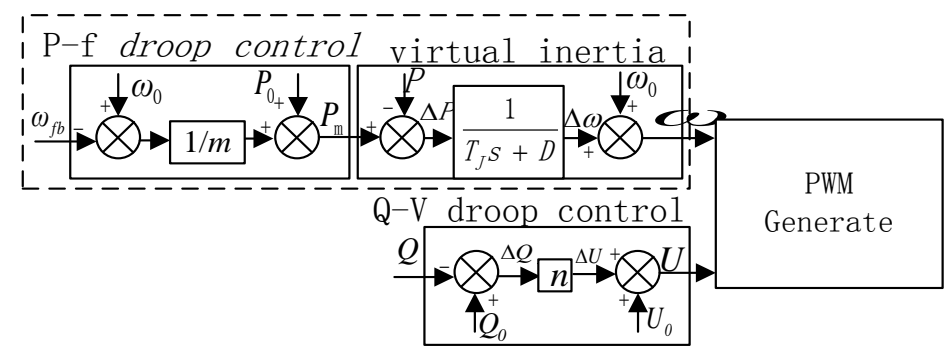

Figure 1. Frequency control diagram of virtual synchronous generator control method. 
and phase between grid and inverter is inconsistent, it will cause voltage switching transient and big fluctuations, affecting the normal operation of the system, or even damage the electricity and power generation equipment [11]. Therefore, the seamless switching between two operating modes not only requires tracing the frequency and phase of grid, but also need to track the output current change during mode switching.

\subsection{Switching from Islanded to Grid-Connected}

In the process of seamless switching, the switch from grid-connected to islanded is different from the other process. The inverter can be directly switched from grid-connected to islanded and will not impact the system. In the process of switching from islanded to grid-connected, it is necessary to process pre-synchronization, phase and voltage amplitude tracking.

\subsubsection{Voltage Synchronization}

For the voltage frequency control method, just set the voltage to the same as the grid voltage it is possible to avoid the impact caused by different voltage amplitudes during switching. However, for the islanded operation mode using the virtual synchronous generator control strategy, voltage regulation is required.

The characteristics of the reactive power and voltage droop control strategy of virtual synchronous generator are shown in Figure 2:

Function as follows:

$$
U=U^{*}-n\left(Q-Q^{*}\right)
$$

When the output voltage of the virtual synchronous generator is not equal to the grid voltage (which is usually the rated value of the virtual synchronous generator), the output voltage needs to be changed to equal to the gird voltage. Set the translation of $U$ as:

$$
\Delta U=\left(k_{p}+\frac{k_{i}}{s}\right)\left(U_{\text {grid }}-U\right)
$$

So the output voltage can be expressed as:

$$
U=U^{*}+\left(k_{p}+\frac{k_{i}}{S}\right)\left(U_{\text {grid }}-U\right)-n\left(Q-Q^{*}\right)
$$

The following formula can be proved in accordance with the literature [12]:

$$
\lim _{t \rightarrow \infty} U(t)=\lim _{s \rightarrow 0} s U(s)=U_{\text {grid }}
$$

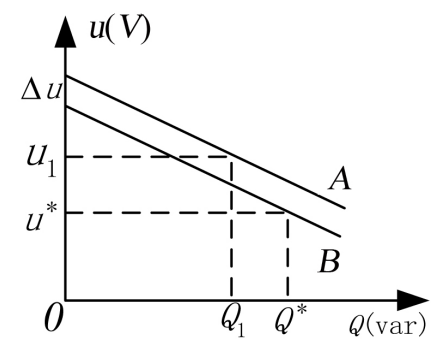

Figure 2. Reactive voltage droop. 
Therefore, the state value of pre synchronization voltage is equal to the grid voltage.

\subsubsection{Phase Pre Synchronization}

Phase pre synchronization can eliminate the phase between inverter and grid. The schematic diagram of the phase pre synchronization control strategy is shown in Figure 4. $\Delta \theta$ is difference between grid phase $\theta g$ and inverter phase $\theta i n v$. Put $\Delta \theta$ into Pi part. The output of the PI is the angular frequency compensation. Only $\theta g$ and $\theta i n v$ is completely equal, the output of PI is 0 , pre synchronization is complete. Otherwise it will always make $\Delta \theta$ get smaller.

\subsubsection{Reference Phase Generation Strategy}

The control strategy can provide continuous reference phase. When switch $=1$, the inverter is grid-connected, select switch $\mathrm{S}$ connected to the 1 channel, $\theta i n v=$ $\theta g$, that is, the phase of the inverter is actually controlled by the grid phase. And when switch $=0, \theta$ inv will equal to the sum of $\omega_{0}$ and the compensation frequency $\omega_{c}$ In the process of switching, the angular frequency of the $\theta i n v$ is always continuous and smooth, although the angular frequency is changed slightly.

On the contrary, when switch changed from 0 to 1 , which is inverter change form islanded to grid-connected, the pre phase synchronization strategy makes the inverter phase is equal to grid phase in advance, so the phase in the process of switching also keeps continuous and smooth. Thus, no matter how switch changes and when to change, the reference phase $\theta i n v$ are continuously changes smoothly.

The principles of the three control strategies are shown in Figure 3:

\subsubsection{Improved Phase Pre Synchronization}

In this paper the phase difference is not directly put into the PI controller, but first gets the remainder of 2 PI, and it is used as the input of the PI controller after a sine function. Because when the phase difference equal to $2 \pi, 4 \pi$ actually should also be considered as synchronization. When the difference is $0.01 \pi$ or $1.99 \pi$, the ideal adjustment strategy should consider the former as 0 and the latter as $2 \pi$. However, if the sine function is not used, the difference is directly put

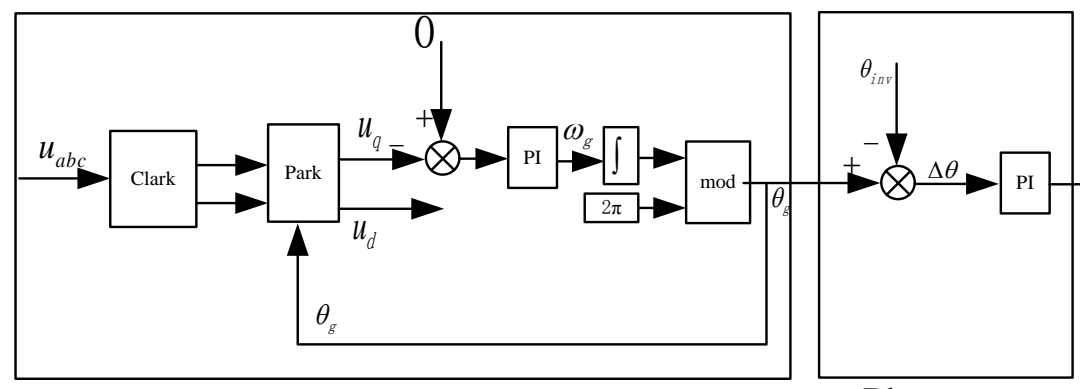

Grid phase calculation
Phase pre synchronization

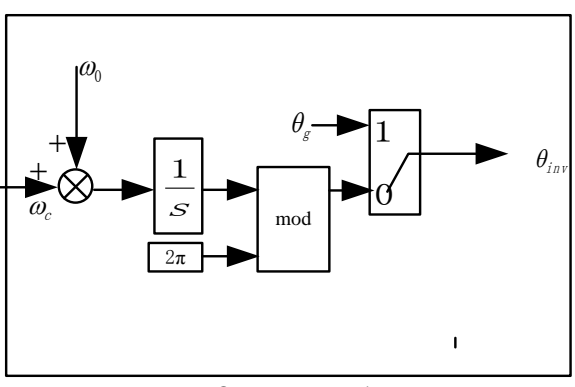

Reference phase generation

Figure 3. Principle diagram of phase-locked synchronous tracking. 
into the PI controller will result in low efficiency and long time tracking. On the other hand, after remainder of $2 \pi$, the output possibly arises from $0.01 \pi$ to $1.99 \pi$ because of small disturbance, but the phase difference of the system is not large. Add sine function can avoid this error.

The principle of the control strategy after adding sine function is shown in Figure 4:

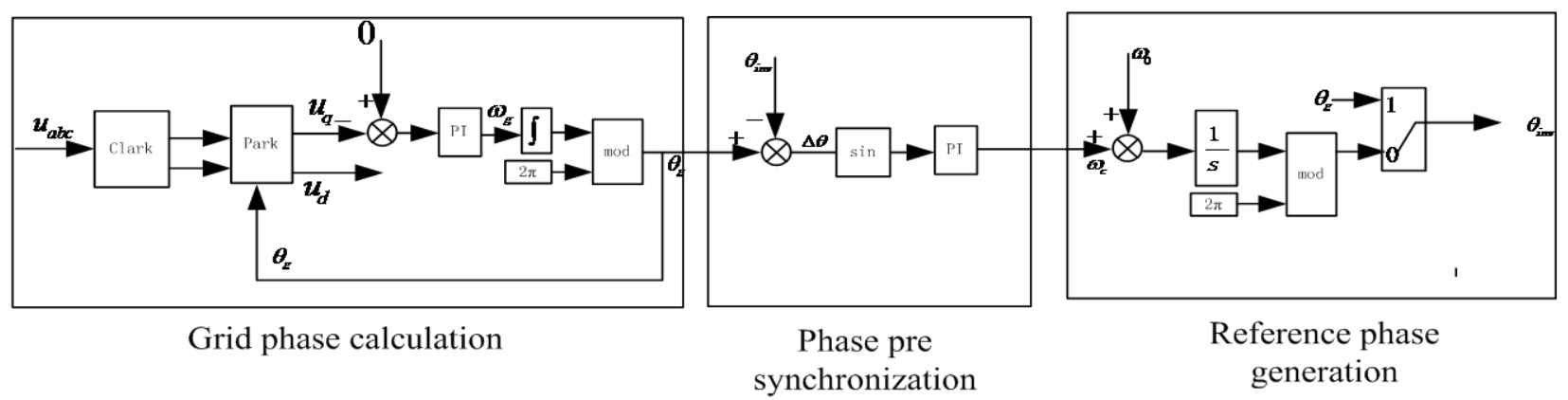

Figure 4. Improved principle diagram of phase-locked synchronous tracking.

\section{Simulation Analysis}

In order to verify the validity of the control strategy, the simulation model (Figure 5) is built in the matlab/simulink, the basic parameters of the circuit are as follows: $1000 \mathrm{~V}$ DC voltage is $1000 \mathrm{~V}$, AC voltage is $220 \mathrm{~V}$, filter inductance is 3 $\mathrm{mH}$, filter resistor $0.002 \mathrm{ohm}$, capacitor $100 \mu \mathrm{F}$, load is $60 \mathrm{~kW}$, the virtual synchronous generator reference power $100 \mathrm{~kW}, 0 \mathrm{kvar}$, reference voltage is $311 \mathrm{~V}$, the reference frequency is $50 \mathrm{~Hz}$. when $\mathrm{t}=0.10 \mathrm{~s}$.

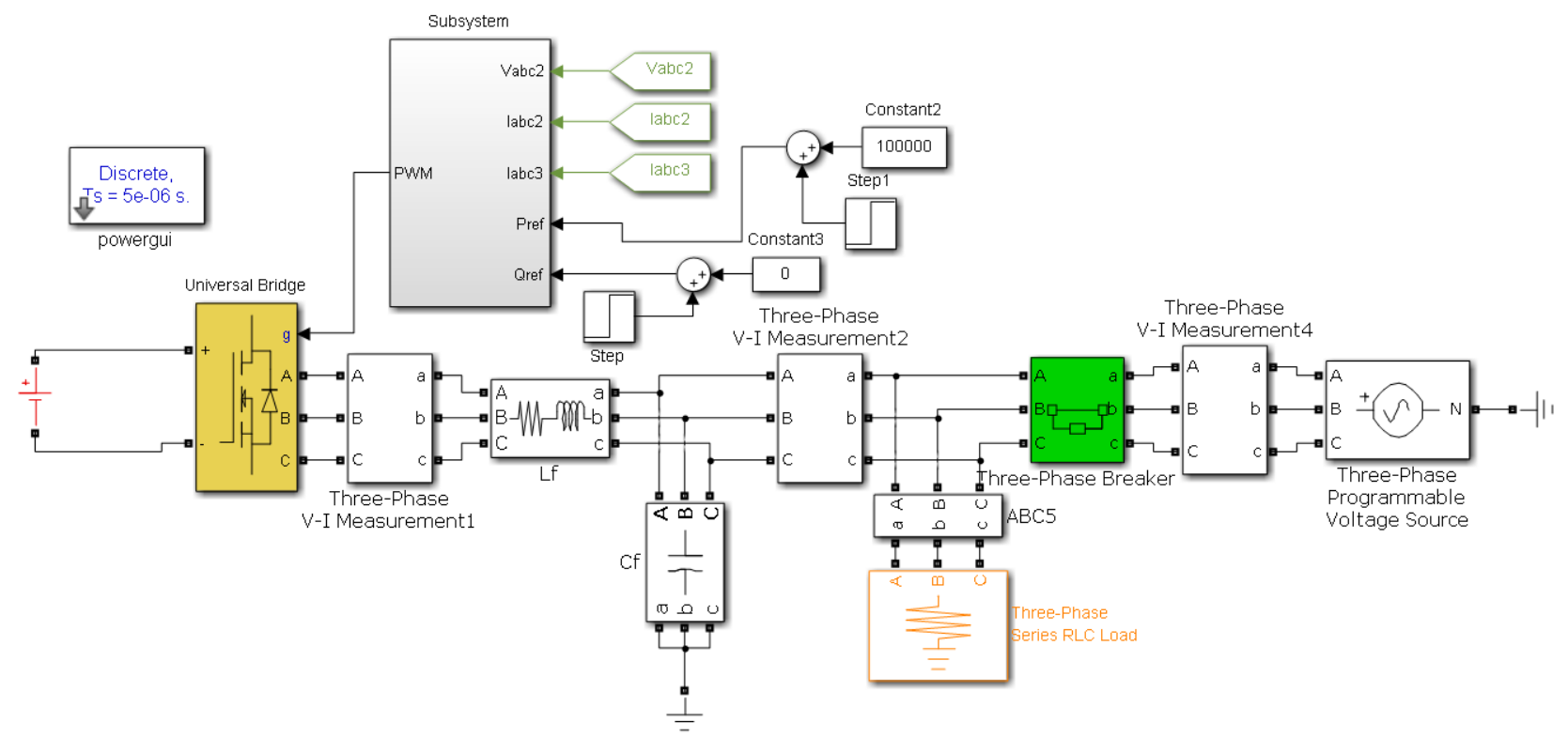

Figure 5. The simulation model.

\subsection{Simulation of Switching from Grid-Connected to Islanded}

The inverter is switched from grid-connected to islanded, the simulation results 
are as follows:

Figure 6 is the output of PLL without improvement, and Figure 7 is the output with improved PLL. This conclusion can be drawn by comparing the two pictures: the improved PLL proposed by this paper can enhance the performance of PLL.

It can be observed from Figure 8 that the voltage waveform is smooth and continuous. In Figure 9, when $t=0.1 \mathrm{~s}$ the inverters is disconnected from grid and do not provide power to the grid, so the current become smaller. But there is no current disturbance during the switching process.

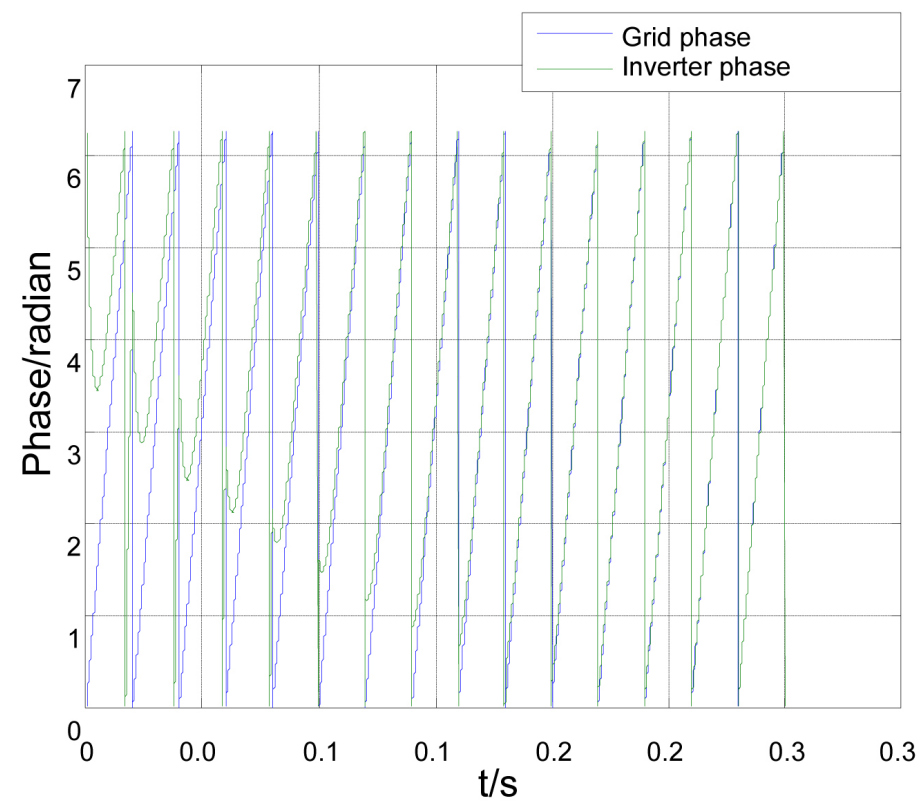

Figure 6. Output of PLL before improvement.

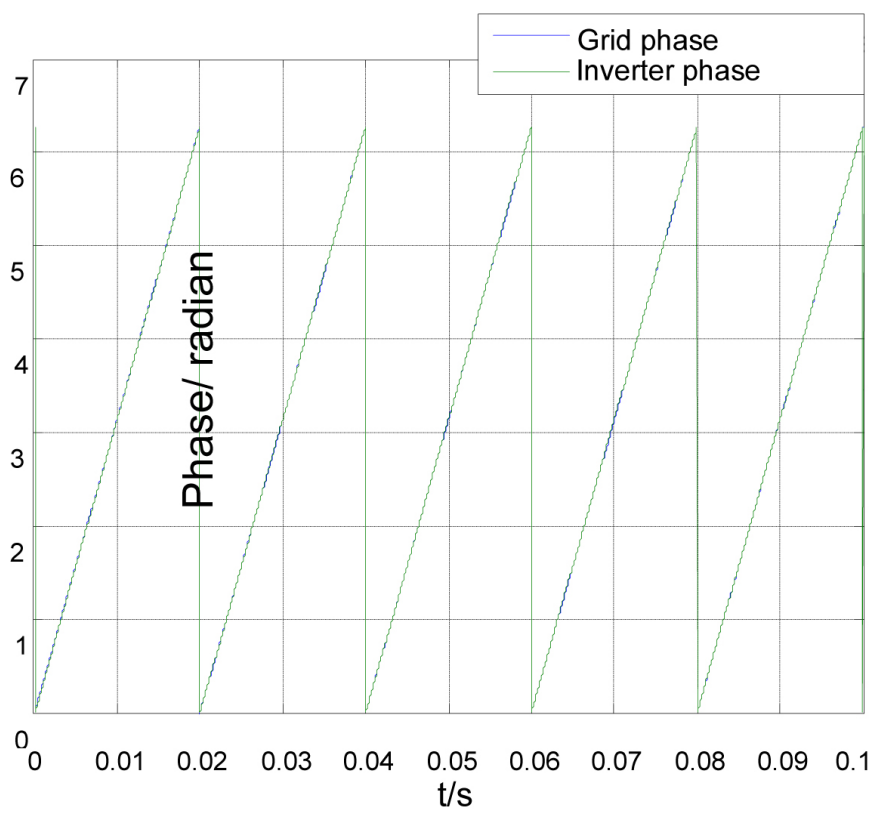

Figure 7. Output of improved PLL. 


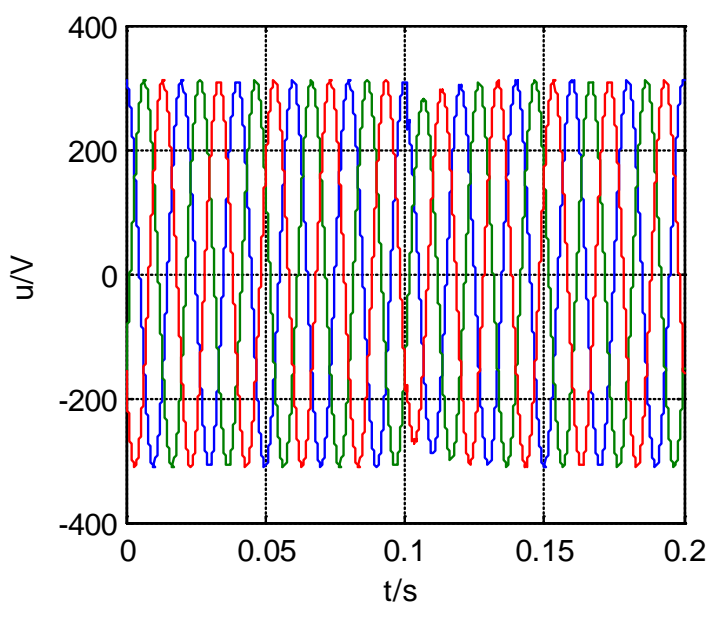

Figure 8. Voltage of inverter.

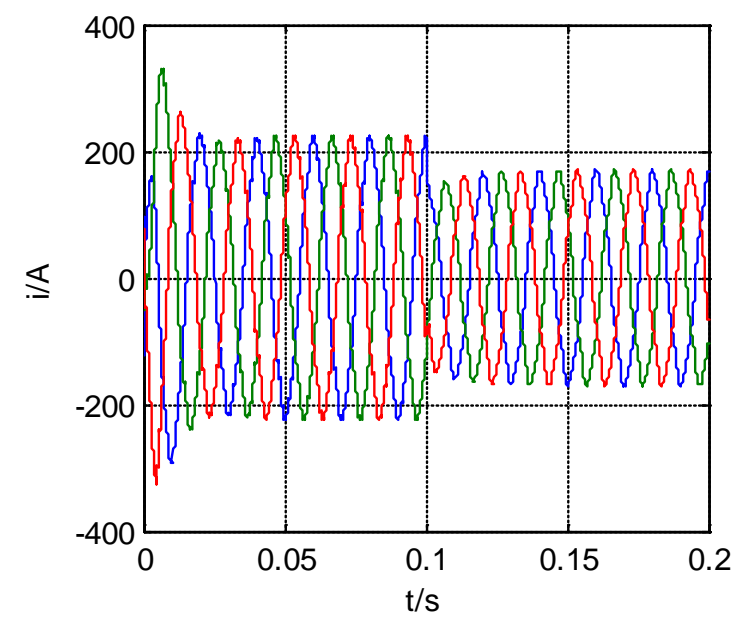

Figure 9. Output current of inverter.

\subsection{Simulation of Switching from Islanded to Grid-Connected}

The parameters of the circuit are the same. When $t=0.1 \mathrm{~s}$ inverter is switched from islanded to grid-connected, the simulation results are as follows:

It can be observed in Figure 10 and Figure 11 that the voltage and current waveform are smooth and continuous, which proves that the control strategy is effective. There is no voltage and current disturbance during the switching process.

\section{Conclusion}

In order to avoid voltage and current mutation when the inverter is switching between grid-connected and islanded, this paper studies the voltage, current and phase trace strategy. By using these strategies the virtual synchronous generator can realize seamless switching. At the same time this paper proposed an improved PLL to elimination the mutations when the phase is near 0 or $2 \pi$. A mathematical model is built in Matlab/Simulink. Simulation results verify the effectiveness and superiority of the proposed strategies. 


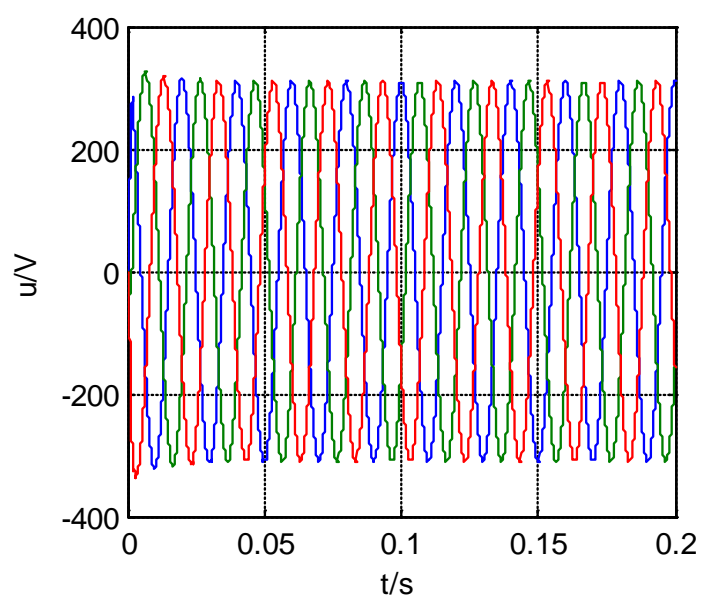

Figure 10. Voltage of inverter.

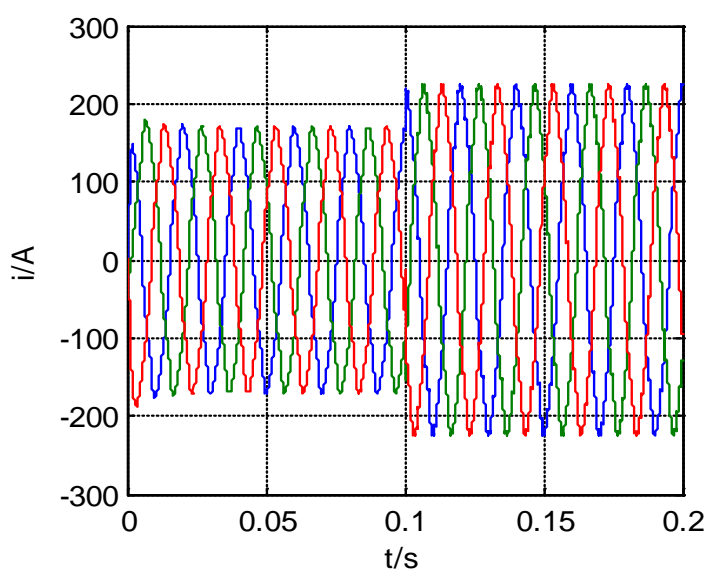

Figure 11. Output current of inverter.

\section{Acknowledgements}

This article is supported by the Fundamental Research Funds for the Central Universities: 14CX02172A.

\section{References}

[1] Yang, X., Du, Y., Su, J., et al. (2016) An Optimal Secondary Voltage Control Strategy for an Islanded MultibusMicrogrid. IEEE Journal of Emerging and Selected Topics in Power Electronics, 4, 1236-1246.

[2] Pathak, G., Singh, B., Panigrahi, B.K. (2016) Back-Propagation Algorithm-Based Controller for Autonomous Wind-DG Microgrid. IEEE Transactions on Industry Applications, 52, 4408-4415.https://doi.org/10.1109/TIA.2016.2581144

[3] Golsorkhi, M.S., Lu, D.D. and Guerrero, J.M. (2017) A GPS-Based Decentralized Control Method for Islanded Microgrids. IEEE Transactions on Power Electronics,32, 1615-1625.https://doi.org/10.1109/TPEL.2016.2551265

[4] Han, Y., Li, H., Shen, P., et al. (2017) Review of Active and Reactive Power Sharing Strategies in Hierarchical Controlled Microgrids. IEEE Transactions on Power Electronics, 32, 2427-2451.https://doi.org/10.1109/TPEL.2016.2569597

[5] Zhong, Q. and Zeng, Y. (2016) Universal Droop Control of Inverters With Different 
Types of Output Impedance. IEEE ACCESS, 4, 702-712.

https://doi.org/10.1109/ACCESS.2016.2526616

[6] Hirase, Y., Sugimoto, K., Sakimoto, K., et al. (2016) Analysis of Resonance in Microgrids and Effects of System Frequency Stabilization Using a Virtual Synchronous Generator. IEEE Journal of Emerging and Selected Topics in Power Electronics,4, $1287-1298$

[7] Wu, H., Ruan, X., Yang, D., et al. (2016) Small-Signal Modeling and Parameters Design for Virtual Synchronous Generators. IEEE Transactions on Industrial Electronics,63, 4292-4303.https://doi.org/10.1109/TIE.2016.2543181

[8] Liu, J., Miura, Y. andIse, T. (2016) Comparison of Dynamic Characteristics Between Virtual Synchronous Generator and Droop Control in Inverter-Based Distributed Generators. IEEE Transactions on Power Electronics,31, 3600-3611. https://doi.org/10.1109/TPEL.2015.2465852

[9] Zhong, Q. and Weiss, G. (2011) Synchronverters: Inverters That Mimic Synchronous Generators. IEEE Transactions on Industrial Electronics,58, 1259-1267. https://doi.org/10.1109/TIE.2010.2048839

[10] Zhong, Q. and Phi-Long, N. (2012) Sinusoid-Locked Loops based on the Principles of Synchronous Machines. Chinese Control and Decision Conference, 2012, 1518-1523. https://doi.org/10.1109/ccdc.2012.6244246

[11] Zhang, Y.F. (2013) Research on Operation Control and Distributed Resource of Micro Grid. Xi'an University of Science and Technology.

[12] Tong, Y.J.(2014) Research on the Switching Control Strategy of Microgrid Islanded And Grid-Connected Modes. Harbin Institute of Technology.

Submit or recommend next manuscript to SCIRP and we will provide best service for you:

Accepting pre-submission inquiries through Email, Facebook, LinkedIn, Twitter, etc. A wide selection of journals (inclusive of 9 subjects, more than 200 journals)

Providing 24-hour high-quality service

User-friendly online submission system

Fair and swift peer-review system

Efficient typesetting and proofreading procedure

Display of the result of downloads and visits, as well as the number of cited articles

Maximum dissemination of your research work

Submit your manuscript at: http://papersubmission.scirp.org/

Or contact epe@scirp.org 